\title{
A Population-Based Study of Peyronie's Disease: Prevalence and Treatment Patterns in the United States
}

\author{
Dana Britt DiBenedetti, ${ }^{1}$ Dat Nguyen, ${ }^{2}$ Laurie Zografos, ${ }^{1}$ \\ Ryan Ziemiecki, ${ }^{1}$ and Xiaolei Zhou ${ }^{1}$ \\ ${ }^{1}$ RTI Health Solutions, RTI International, Research Triangle Park, NC 27709, USA \\ ${ }^{2}$ Auxilium Pharmaceuticals, Inc., Malvern, PA 19355, USA \\ Correspondence should be addressed to Dana Britt DiBenedetti, ddibenedetti@rti.org
}

Received 3 May 2011; Revised 23 June 2011; Accepted 27 June 2011

Academic Editor: Peter E. Clark

Copyright (C) 2011 Dana Britt DiBenedetti et al. This is an open access article distributed under the Creative Commons Attribution License, which permits unrestricted use, distribution, and reproduction in any medium, provided the original work is properly cited.

\begin{abstract}
Purpose. To estimate the US prevalence of Peyronie's disease (PD) from patient-reported data and to identify diagnosis and treatment patterns. Methods. 11,420 US males $\geq 18$ years old completed a brief web-based survey regarding the presence of PD, past treatments, and penile symptoms (Phase 1). Phase 1 respondents with PD diagnosis, history of treatment, or PD-related symptoms then completed a disease-specific survey (Phase 2). Results. Estimated prevalence of PD ranged from $0.5 \%$ (diagnosis of $\mathrm{PD}$ ) to $13 \%$ (diagnosis, treatment, or penile symptoms). Thirty-six percent of Phase 2 participants reported that penile symptoms interfered with sexual activities. Of participants who sought treatment for penile symptoms $(n=128), 73 \%$ initially saw a primary care physician, 74\% did not receive treatment from their first doctor, and 92\% were not diagnosed with PD. Conclusions. PD may be underdiagnosed/undertreated in the US. Improved awareness is needed of PD symptoms and treatment options among health care professionals.
\end{abstract}

\section{Introduction}

Peyronie's disease (PD) is a progressive fibrotic tissue disorder with unknown etiology [1-3]. It is a connective tissue disorder of the penile tunica albuginea that results in the formation of a palpable scar or hard plaque, most commonly on the dorsal surface of the penis, which may cause a curvature deformity and changes in the length or circumference of the penis while erect. Penile folding or collapsing during intercourse, penile pain, and erectile dysfunction (ED) are also associated with $\mathrm{PD}[1]$. In a recent retrospective study of 1,001 patients with $\mathrm{PD}, 58.1 \%$ of patients reported having ED [4]. PD may also limit the ability to have intercourse and may make intercourse less enjoyable, more awkward, and even impossible. PD can be psychologically and physically devastating for patients and can also negatively impact partner relationships $[5,6]$.

The disease is not well understood, and consequently, patients are often misdiagnosed (e.g., with ED) and the time to diagnosis and treatment can be long. Current theories regarding the cause of $\mathrm{PD}$ suggest that a variety of factors may be involved, such as a traumatic event, sometimes related to sexual intercourse, the presence of genetic predisposition, or occurrence of abnormal wound healing, including involvement of transforming growth factor $\beta$ - 1 or other profibrotic factors $[7,8]$. Convincing evidence regarding the pathophysiology, diagnosis, and treatment of PD continues to elude physicians [9].

To date, there are no Food and Drug Administration(FDA)-approved, nonsurgical options for treatment of PD, and clinically proven treatment options are limited. Current nonsurgical treatment options for PD include oral, transdermal, or intralesional injection, extracorporeal shock wave therapy, or external traction therapy $[1,10-13]$. The efficacy of many nonsurgical treatments is unknown due to underpowered and methodologically heterogeneous treatment studies [10]. Surgical interventions for PD may follow unsuccessful nonsurgical treatment options and are primarily considered for patients with deformity that impairs sexual function [14]. It is recommended that surgery be delayed 
TABle 1: Prevalence of Peyronie's disease from the literature.

\begin{tabular}{llc}
\hline & Patient population & $\begin{array}{c}\text { Prevalence } \\
(\%)\end{array}$ \\
\hline Arafa et al. 2007 [17] & $\begin{array}{l}\text { Diabetic patients with } \\
\text { erectile dysfunction } \\
\text { Men screened for } \\
\text { prostate cancer } \\
\text { Mulhall et al. 2004 [21] }\end{array}$ & 20.3 \\
El-Sakka 2006 [18] & $\begin{array}{l}\text { Patients with erectile } \\
\text { dysfunction } \\
\text { General population }\end{array}$ & 7.9 \\
La Pera et al. 2001 [19] & $\begin{array}{l}\text { Men older than 50 years } \\
\text { undergoing prostate }\end{array}$ & 3.1 \\
Rhoden et al. 2001 [22] & 3.67 \\
$\begin{array}{l}\text { Schwarzer et al. 2001 } \\
\text { [23], Sommer et al. 2002 }\end{array}$ & $\begin{array}{l}\text { General population } \\
\text { [24] }\end{array}$ & 3.2 \\
Lindsay et al. 1991 [20] & General population & 0.39 \\
\hline
\end{tabular}

until the disease has stabilized for at least 6 to 12 months and the active inflammatory disease process involving penile pain and recent changes in penile deformity has concluded [1]. Surgical correction has its limitations, including penile shortening in many procedures, recurrence of curvature, altered penile sensation, development of new-onset $\mathrm{ED}$, and the potential rare complications of surgery, such as bleeding or infection [14-16].

The prevalence of PD is not known. Studies of PD prevalence are limited and inconsistent; estimates have ranged from $0.39 \%$ to greater than $20 \%$ (see Table 1) [17-24]. Prevalence can range based on study design or inclusion of patients with different comorbidities within the study population (e.g., older age, diabetes, and ED). In addition, the actual occurrence of this disease within the population may be higher due to patients' reluctance to come to their physician for treatment and diagnosis of this embarrassing condition [25]. Limited understanding of PD in the medical community may also contribute to underdiagnosis.

The current study was motivated by the lack of the current PD epidemiological data from the general US population and the need to understand how patients and physicians perceive this disease in regards to diagnosis and treatment. The current study is web-based survey of US male adults aged 18 years or older who were enrolled in a probabilitybased panel of research subjects representative of the full US population (Knowledge Networks; KN) [26]. The study objectives were (1) to estimate the prevalence of PD in the general US male population, (2) to determine the time from first symptom noticed to medical treatment, and (3) to describe diagnosis and treatment patterns. Analyses of these objectives were based on patient-reported data.

\section{Methods}

2.1. Study Design. This cross-sectional, population-based survey was conducted in 2 phases (Figure 1). In the initial phase (Phase 1), participants from the KN online panel were screened for the presence of current symptoms of PD, past

\section{KN database}

16,000 invited panel participants (men $\geq 18$ years old)

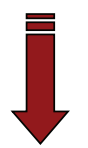

11,420 participants completed Phase 1 survey
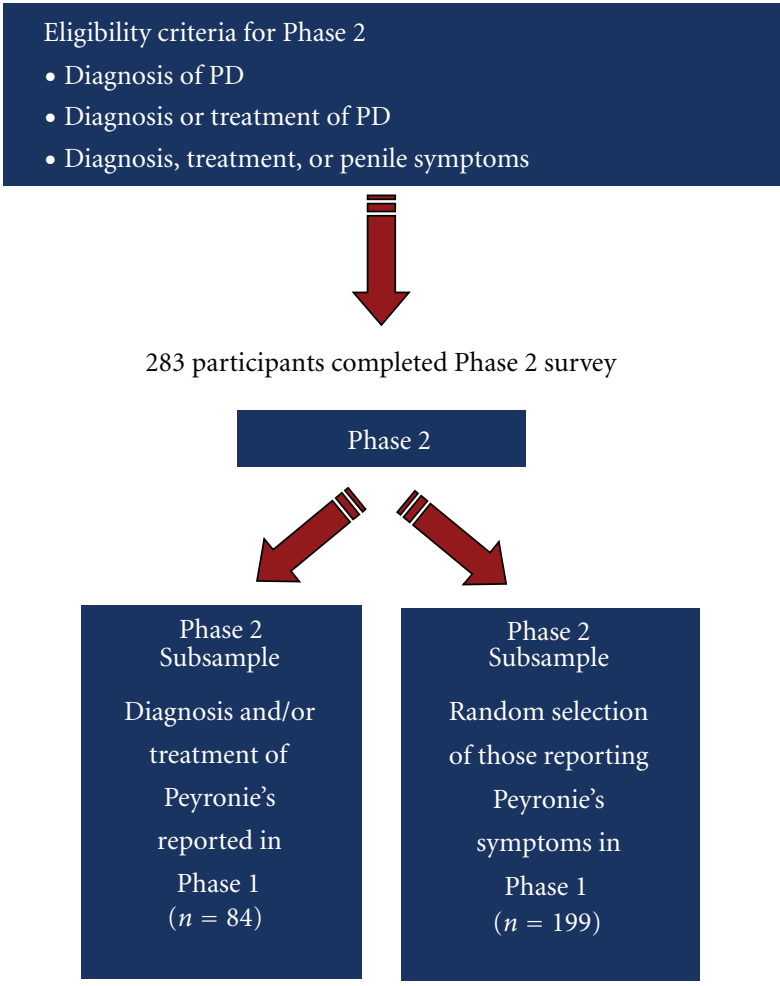

Figure 1: Diagram of study design. Data for this study were collected in 2 phases. In Phase 1, panel participants were screened for the presence of symptoms, past treatment, and a diagnosis of Peyronie's disease. In Phase 2, eligibility to complete the full survey was determined by participants' responses to the screening items in Phase $1 . \mathrm{KN}=$ Knowledge Networks.

surgical or nonsurgical treatments, and a diagnosis of PD. Data from Phase 1 was used to estimate the prevalence of PD in the general US population and to determine eligibility to complete the full survey in Phase 2. In the Phase 2 portion of the study, a subsample of Phase 1 participants meeting the eligibility criteria for PD were invited to complete the PD survey (see the Appendix), which focused on the presence and severity of current symptoms, family history, and treatment history for penile symptoms.

The KN panel, a proprietary web-enabled panel of individuals who have agreed to participate in ongoing survey research is the only known online panel based on a randomdigit-dialing sample of the full US population, ensuring that the panel is representative of the US population [26]. KN provides panelists "points" that can be redeemed for cash at regular intervals for panel participation (for those with 
Internet access) or with web-enabled technology to ensure that those who would not otherwise have access to the Internet are able to participate in KN surveys [26]. The KN panel has been used to estimate prevalence previously in several different studies [27-29].

The current study was structured in a way that allowed for patient confidentiality in both phases: identifying patient information was never transmitted or provided to study personnel and $\mathrm{KN}$ did not link patient contact information and survey responses. Following ethics committee approval by RTI International's Institutional Review Board, screening in Phase 1 was fielded from November 6, 2007, through December 9, 2007, and the Phase 2 survey was fielded from March 20, 2008, through March 31, 2008. Prior to administration of either Phase 1 or Phase 2 surveys, all participants provided written informed consent.

2.2. Participants. A total of 16,000 men aged 18 years and older residing in the US were randomly selected from the KN online panel and invited to participate in the current study. Individuals eligible for Phase 1 included all adult men (aged 18 years or older) who were KN panel members at the time of Phase 1 recruitment. Eligibility for the PD full survey (Phase 2) was based on responses to the screening questions in Phase 1. Specifically, Phase 1 respondents eligible for Phase 2 were those who reported 1 or more of the following criteria at screening:

(1) ever received a diagnosis of PD by a doctor or other health care professional,

(2) ever received either surgery or a nonsurgical procedure to correct the shape of the penis,

(3) currently have at least 1 of the following symptoms:

(i) a lump or bump (excluding genital warts, pimples, and blisters) under the skin of the penis when the penis is not erect,

(ii) an area of unusual firmness or hardened tissue (excluding genital warts, pimples, and blisters) under the skin of the penis when the penis is not erect,

(iii) a change in erect penis that includes at least 1 of the following symptoms:

(a) a significant bend or curve of the penis,

(b) an indentation on 1 or both sides of the penis,

(c) a noticeable narrowing of the penis, like an hourglass or band around the penis, or a folding, like a hinge, of the penis during sexual intercourse.

In addition, respondents with chordee (congenital curvature of the penis) were eligible only if they reported (1) one of the above-mentioned symptoms other than a significant bend or curve of the penis or (2) a diagnosis of PD. A total of 27 patients had chordee and 12 of them were eligible for Phase 2, and all of them met additional criteria for inclusion in the study. Specifically, 2 of them reported diagnosis of PD,
1 had received treatment for $\mathrm{PD}$, and 9 had other qualifying symptoms of PD.

2.3. Sampling Method for the Phase 2 Peyronie's Disease Survey. Participants invited to complete Phase 2 were selected using a stratified random sampling approach based on the following 2 strata: (1) participants reporting treatment and/or diagnosis (Stratum 1) and (2) participants reporting symptoms only (Stratum 2). To ensure an adequate sample size to evaluate treatment patterns, respondents reporting prior treatment or a diagnosis for PD in Phase 1 were oversampled in Phase 2.

After excluding respondents who were no longer active in the KN panel, all respondents from Stratum 1 (diagnosis and/or treatment) were invited to complete the Phase $2 \mathrm{PD}$ survey. In addition, to ensure that at least 200 completed patient surveys could be obtained, 314 participants from Stratum 2 (symptoms only) were randomly selected to complete the Phase 2 PD survey.

2.4. Questionnaire Content. The Peyronie's portion of the screener administered in Phase 1 contained questions assessing the presence of various penile-related symptoms, diagnosis of $\mathrm{PD}$, and past surgical or nonsurgical treatments for penile-related symptoms (see the Appendix).

The Peyronie's survey in Phase 2 focused on the presence and severity of current symptoms, family history, and treatment history for penile symptoms (e.g., specific symptom first noticed, time from noticing first symptom until seeking medical treatment, other symptoms noticed, types of treatment received and success of each treatment type, length of treatment/duration of care, number of surgeries and/or nonsurgical procedures, diagnoses received, and types of physicians treating and/or diagnosing the disease).

\subsection{Data Analysis}

2.5.1. Prevalence Estimates. The prevalence estimates of PD were based on self-reported data from Phase 1 and adjusted to represent the US population by using statistical weights provided by KN. These weights are designed to (1) account for the known sources of deviation from an equal-probability selection design during formation of the $\mathrm{KN}$ panel, (2) reduce bias due to noncoverage of nontelephone households, and (3) reduce the nonresponse bias potentially introduced during data collection for outcomes highly correlated with demographic and geographic characteristics.

Three different prevalence estimates for PD were calculated. The numerators for the prevalence estimates of PD were derived using the following 3 criteria, ordered from most to least stringent, and the denominator was the number of individuals who completed Phase 1.

Criterion 1. Participant has received a diagnosis of PD from a doctor or other health care professional.

Criterion 2. Participant meets Criterion 1 or has ever had surgery and/or a nonsurgical procedure to correct the shape of the penis. 
TABLE 2: Demographic characteristics of Phases 1 and 2 male participants.

\begin{tabular}{|c|c|c|c|c|}
\hline \multirow[b]{2}{*}{ Characteristic } & \multirow[b]{2}{*}{ Category } & \multirow[b]{2}{*}{$\begin{array}{l}\text { Phase } 1 \text { participants } \\
\quad(n=11,420)\end{array}$} & \multicolumn{2}{|c|}{ Phase 2 participants $(n=283)$} \\
\hline & & & $\begin{array}{l}\text { With diagnosis/treatment } \\
\qquad(n=84)\end{array}$ & $\begin{array}{c}\text { With symptoms and } \\
\text { no diagnosis/treatment } \\
(n=199)\end{array}$ \\
\hline & & $n(\%)$ & $n(\%)$ & $n(\%)$ \\
\hline \multirow{3}{*}{ Age (years) } & Mean (SD) & $52.7(15.0)$ & $59.6(11.9)$ & $49.6(17.0)$ \\
\hline & Median & 53 & 60 & 50 \\
\hline & Range & $18-101$ & $20-87$ & $18-89$ \\
\hline \multirow{4}{*}{ Race } & White, non-Hispanic & $9803(86 \%)$ & $76(90 \%)$ & $137(69 \%)$ \\
\hline & Black, non-Hispanic & $571(5 \%)$ & $3(4 \%)$ & $25(13 \%)$ \\
\hline & Other, non-Hispanic & $544(5 \%)$ & $5(6 \%)$ & $14(7 \%)$ \\
\hline & Hispanic & $502(4 \%)$ & $0(0 \%)$ & $23(12 \%)$ \\
\hline \multirow{4}{*}{ Education } & Less than high school & $588(5 \%)$ & $3(4 \%)$ & $16(8 \%)$ \\
\hline & High school & $2098(18 \%)$ & $8(10 \%)$ & $57(29 \%)$ \\
\hline & Some college & $3898(34 \%)$ & $32(38 \%)$ & $58(29 \%)$ \\
\hline & Bachelor's degree or higher & $4836(42 \%)$ & $41(49 \%)$ & $68(34 \%)$ \\
\hline
\end{tabular}

SD: standard deviation.

Criterion 3. Participant meets Criterion 2 or has penile plaque or a deformity as indicated by an affirmative response to at least 1 of the following: a lump or bump under the skin of the penis when penis is not erect, unusual firmness or hardened tissue under the skin of the penis when penis is not erect, bend or curve when the penis is erect, indentation when the penis is erect, noticeable narrowing, like an hourglass, when the penis is erect, or folding like a hinge when the penis is erect

A participant with chordee did not meet PD criteria unless he also reported at least 1 of the following symptoms: lump, firmness, indentation, narrowing or folding, or a diagnosis of PD by a physician or other health care provider.

2.5.2. Analysis of Phase 2 Peyronie's Disease Survey. As described previously, the PD survey was administered in Phase 2 to a stratified random sample of patients indicating a diagnosis of $\mathrm{PD}$, and/or treatment for penile symptoms (Stratum 1), or presence of penile symptoms (Stratum 2). Because patients reporting a diagnosis or treatment were oversampled, summary statistics (i.e., means or percentages) were calculated using weighted averages of the stratumspecific estimates to obtain an overall estimate among the eligible participants across the 2 strata (treatment/diagnosis and symptom only) [30]. No imputations were made for missing values. When calculating percentages, participants who did not answer a particular question were excluded from the denominator for that question.

\section{Results}

Of the 16,000 men aged 18 years and older who were randomly selected from the pool of KN panel members and invited to participate in Phase 1, a total of 11,420 completed the screening survey for a response rate of $71 \%$. In Phase 1 of the study, 415 PD patients were identified (101 of them reported a PD diagnosis and/or surgical/nonsurgical treatment) and invited to complete a full survey in Phase 2. Of those invited to participate, $283(68 \%)$ consented and completed the PD full survey in Phase 2.

3.1. Demographic Characteristics. Table 2 presents unweighted demographic characteristics for all respondents in Phase 1 as well as respondents to the PD survey in Phase 2. The mean age of all respondents in Phase 1 was $52.7(\mathrm{SD}=15.0)$ years. In Phase 2, the mean age of the respondents who had received a diagnosis or treatment was $59.6(\mathrm{SD}=11.9)$ years, while the mean age for respondents who had symptoms but were not diagnosed/treated was $49.6(\mathrm{SD}=17.0)$ years. The majority of respondents across both phases were white $(86 \%)$ and had completed at least a high school level of education. Respondents with symptoms but no diagnosis/treatment tended to be younger, Black and Hispanic, and less likely to have post-high-school education compared to those with diagnosis or treatment.

3.1.1. Prevalence Estimate. The estimated prevalence of $\mathrm{PD}$ based on the 3 criteria ranged from $0.5 \%$ to $13 \%$, ordered from most to least stringent criteria (Table 3 ).

3.2. Peyronie's Disease Symptoms and Treatment Patterns. Results from the Phase 2 survey indicate that $21 \%$ of patients with $\mathrm{PD}$ diagnosis, treatment, or symptoms reported having a lump or bump under the skin of their penis, and $21 \%$ reported unusual firmness or hardened tissue under the skin of their penis (Table 4). Thirty-seven percent indicated that these symptoms affected the shape of their penis. Most patients (95\%) reported no painful erections or pain during intercourse. However, 36\% reported penile-related symptoms that interfered with sexual activities. The most common first penile symptom noticed was a significant bend or curve $(32 \%)$. Other first penile-related symptoms 
TABLE 3: Estimated prevalence of Peyronie's disease in US males in 2007.

\begin{tabular}{|c|c|c|}
\hline \multirow[b]{2}{*}{ Disease criteria } & \multicolumn{2}{|c|}{ Phase 1 respondents $(n=11,420)$} \\
\hline & Prevalence (\%) & $95 \% \mathrm{CI}$ \\
\hline $\begin{array}{l}\text { Criterion 1: } \\
\text { Diagnosis of PD }\end{array}$ & 0.5 & $0.4-0.7$ \\
\hline $\begin{array}{l}\text { Criterion 2: } \\
\text { Diagnosis or } \\
\text { treatment of } \mathrm{PD}\end{array}$ & 0.8 & $0.5-1.0$ \\
\hline $\begin{array}{l}\text { Criterion 3: } \\
\text { Diagnosis, } \\
\text { treatment, or any } \\
\text { symptom of PD }\end{array}$ & 13.1 & $12.0-14.1$ \\
\hline
\end{tabular}

CI: confidence interval.

Note: Prevalence estimates are weighted estimates from 11,420 male respondents.

commonly reported include erections not hard enough for sexual intercourse $(20 \%)$, head of penis less hard (12\%), lump or bump under the skin (11\%), or shortening of penis $(10 \%)$.

Of the 283 PD patients, 128 reported seeing a doctor for the treatment of penile-related symptoms at some time during their lifetime. Among these patients, $68 \%$ reported seeing a doctor when they first noticed symptoms; the mean time to see the doctor was 16.8 ( $\mathrm{SD}=5.5)$ months. Onethird (32\%) of patients spoke with a doctor at a later time; the mean time to see the doctor was $46.2(\mathrm{SD}=8.4)$ months. The majority $(73 \%)$ of PD patients seeking treatment first saw a primary care physician (PCP), and $22 \%$ first saw a urologist/urology surgeon (note: from here forward, the term urologist will include urology surgeon). The most common symptoms that prompted seeking treatment were erections not hard enough for intercourse (51\%), lump or bump under the skin of the penis (13\%), and significant bend or curve in the penis $(10 \%)$.

Only $8 \%$ of treatment-seeking patients reported receiving a diagnosis of PD from the first doctor seen for penile symptoms; $48 \%$ reported receiving a diagnosis of ED. Among the few that were diagnosed with $\mathrm{PD}, 59 \%$ received the diagnosis from a urologist, and $41 \%$ received the diagnosis from their PCP.

Treatment was often not given (49\%), and patients were often advised to "wait and see" (25\%) from the first doctor seen for penile symptoms. When treatment was eventually recommended at any doctor visit, the most commonly reported treatments were ED treatment (17\% of those who saw a doctor), topical gel applied to the skin of the penis (7\%), vitamin B or potaba (7\%), vacuum or stretching therapy (5\%), and vitamin $\mathrm{E}(5 \%)$. The mean time to treatment from the first noticed symptom was $8.9(\mathrm{SD}=6.7)$ months (topical gel) to $37.0(\mathrm{SD}=12.3)$ months ( $\mathrm{ED}$ therapy).

3.2.1. Summary of Surgical Procedures. Sixteen PD patients reported undergoing surgery for $\mathrm{PD}$; of these, 14 patients reported 1 surgery and 2 patients reported 3 or more surgeries. A urologist performed the initial surgery in $81 \%(13 / 16)$ of participants. The mean time from first noticing a penile symptom until the first surgery was 31.8 months (SD $=64.2$ months). The mean time from first diagnosis to first surgery was 6.3 months ( $\mathrm{SD}=6.8$ months). Among respondents, 5 patients reported receiving a prosthetic penile implant, and 2 patients reported surgical grafting ( 6 patients reported "other" surgical procedure). Of the 16 patients who had surgery performed, 13 reported that the first surgery corrected the penile-related symptoms, and 11 reported that symptoms did not return, and no new symptoms were reported following surgery.

3.2.2. Summary of Nonsurgical Injection Procedures. Twelve PD patients reported injections to treat penile symptoms; 10 patients reported 1 series of injections, and 2 patients reported 5 or more injection series. The first injection series was performed by a urologist in $42 \%$ (5/12) of participants, a PCP in $25 \%(3 / 12)$ of patients, and a sexual medicine specialist in $25 \%(3 / 12)$ of patients. Among 10 respondents who provided information around timing of injections, the first injection procedure was an average of 9.7 months ( $\mathrm{SD}=14.4$ months) from the time the first symptom was noticed. Three of these 10 respondents were diagnosed, and the average time to the first injection series from the time of first diagnosis was 2.3 months ( $\mathrm{SD}=2.5$ months). Four respondents knew the type of medication received in the first injection series; 2 reported verapamil, 1 reported testosterone, and 1 reported an unspecified "other" injection. Six out of 12 patients who had injections to treat penile symptoms reported that the injections corrected the penilerelated symptoms, and 4 patients reported that symptoms did not return, and no new symptoms were reported following the procedure.

\section{Discussion}

Although PD has been recognized for over 200 years, no consensus exists with regard to the etiology, prevalence, treatment, or even the definition of this condition. The current study, the first large-scale, web-based population survey of PD among men in the US, showed the estimated prevalence of $\mathrm{PD}$ in the US to range from $0.5 \%$ (diagnosis of PD) to $13 \%$ (diagnosis, treatment, or penile symptoms) using criteria described previously. The estimate of $0.5 \%$ was based on respondent-reported diagnosis by a physician. The study did not collect information on what exams were used by the physician to arrive at the diagnosis. However, this number may be underestimated because most of the responders of the study did not see a physician even though they experienced penile symptoms. When including those reporting penile symptoms, the prevalence increased to $13 \%$. The higher prevalence of symptoms of PD compared with the actual diagnosis suggests that PD may be underdiagnosed in the US. Additionally, diagnosis of ED and high usage of ED-related treatments may actually indicate misdiagnosis of PD symptoms. Underreporting of PD may occur because affected individuals are not comfortable discussing symptoms with health care professionals or are unaware of effective treatment options. In addition, health care professionals 
TABLe 4: Summary of Peyronie’s disease symptoms in participants with symptoms, treatment, or diagnosis $(n=283)$.

\begin{tabular}{|c|c|c|}
\hline & Statistic or category & $\begin{array}{l}\text { Participants }(n=283) \\
(n, \% *)\end{array}$ \\
\hline \multirow[t]{3}{*}{ Lump or bump under skin of penis } & Yes & $60(21)$ \\
\hline & No & $222(79)$ \\
\hline & Missing & 1 \\
\hline \multirow[t]{3}{*}{ Unusual firmness or hardened tissue under skin of penis } & Yes & $69(21)$ \\
\hline & No & $210(79)$ \\
\hline & Missing & 4 \\
\hline \multirow{2}{*}{$\begin{array}{l}\text { Lump/bump, firmness, or hardened tissue affect the shape of } \\
\text { penis (if yes to either } 1 \text { of the above } 2 \text { symptoms, } n=87 \text { ) }\end{array}$} & Yes & $48(37)$ \\
\hline & No & $39(63)$ \\
\hline \multirow{2}{*}{$\begin{array}{l}\text { Significant bend or curve compared to a younger age (erect } \\
\text { penis) }\end{array}$} & Yes & $177(59)$ \\
\hline & No & $106(41)$ \\
\hline \multirow[t]{13}{*}{ First penis-related symptom noticed } & Lump or bump under the skin & $24(11)$ \\
\hline & $\begin{array}{l}\text { Area of unusual firmness or } \\
\text { hardened tissue under the skin }\end{array}$ & $13(4)$ \\
\hline & $\begin{array}{l}\text { Significant bend or curve not } \\
\text { previously noticed }\end{array}$ & $95(32)$ \\
\hline & Indentation on 1 or both sides & $7(2)$ \\
\hline & $\begin{array}{l}\text { Noticeable narrowing of the } \\
\text { penis (hourglass or bandlike) }\end{array}$ & $4(2)$ \\
\hline & $\begin{array}{l}\text { Hinge-like folding of penis } \\
\text { during sexual intercourse }\end{array}$ & $7(3)$ \\
\hline & Shortening of penis & $20(10)$ \\
\hline & Head of penis less hard & $26(12)$ \\
\hline & Painful erections & $4(<1)$ \\
\hline & Pain during sexual intercourse & $5(2)$ \\
\hline & $\begin{array}{l}\text { Erections not hard enough for } \\
\text { sexual intercourse }\end{array}$ & $51(20)$ \\
\hline & Other & $8(3)$ \\
\hline & Missing & 19 \\
\hline
\end{tabular}

${ }^{*}$ Percentages are weighted averages of the stratum-specific estimates.

may not recognize symptoms when presented by patients, or they may not perform physical exams themselves and may instead refer patients to a specialist. Not all health care professionals may be properly trained in this area of research, and thus, they may be unaware of available treatments.

It has recently been shown that PCPs and urologists may not be aware of recent findings related to the prevalence of $\mathrm{PD}$, its association with $\mathrm{ED}$, and its responsiveness to available treatments [31]. Results of a survey by LaRochelle and Levine found that, contrary to new information regarding PD, many physicians (63\% of PCPs and $41 \%$ of urologists) continue to believe the prevalence of PD is below $1 \%$, and $17 \%$ of PCPs and $38 \%$ of urologists believed that the disease remits spontaneously in more than $50 \%$ of cases [31], despite the lack of data from available research supporting these beliefs.

Among PD patients who reported a diagnosis, treatment, or penile symptoms related to $\mathrm{PD}$, interference in sexual activities was reported by approximately one-third. Thirtyone percent of patients reported either a lump/bump or an unusual firmness or hardened tissue under the skin of the penis. While this number of patients who identified a palpable plaque may seem low, a study of more than 1,500 patients with PD found similar number of patients reporting plaques $(39 \%)$, so these results may be more common than originally suspected [32]. Penile pain is an important consideration in patients with PD, particularly in the early, acute phase of PD [33, 34]; however, pain was not declared by many patients in this study. We cannot make definitive conclusions about the absence of reported pain because this study asked about current symptoms and symptoms first noticed, not the symptoms ever experienced. It is possible that some patients experienced pain at some point during the course of the disease, but this study was not intended to capture all symptoms ever experienced.

Regardless of the fact that patients reported a wide array of penile symptoms, fewer than half of PD patients reported seeking treatment. Many patients may be reluctant to come to their physician for treatment and diagnosis of this embarrassing condition [25]. Several factors have been identified that predict which patients are more inclined to delay treatment, including older age, being in a long-term 
relationship, having a partner, being heterosexual, and the presence of simple penile deformity [35]. Of those seeking medical treatment for penile symptoms, most initially saw a PCP, and the average duration of time to a doctor visit was within a year and a half of noticing a penile symptom. Approximately one-third of PD patients did not see a doctor until 4 years after the emergence of penile symptoms. Consistent with the possibility of underdiagnosis and undertreatment of PD in the US, only $8 \%$ of PD patients received a diagnosis of PD from the first doctor seen; the most frequent diagnosis was ED. Approximately three-quarters of the patients received no treatment from the first doctor seen, and $15 \%$ received treatment related to ED. These results further indicate that PD is not well understood, and the time to appropriate diagnosis and treatment can be long.

The observed treatment patterns for patients with $\mathrm{PD}$ include surgical and nonsurgical procedures. There are currently no FDA-approved nonsurgical options. Therefore, physicians have to base treatment recommendations for nonsurgical options on limited placebo-controlled clinical trial support $[9,36,37]$. This may lead some physicians to offer expectant management as opposed to potentially ineffective nonsurgical therapies [38]. Penile operations and injection treatments were uncommon among PD patients. Urologists most frequently performed these procedures, followed by PCPs and sexual medicine specialists for injection procedures. The median duration of time to receive treatment following diagnosis of PD was approximately 2 months earlier for injection procedures compared with surgery and, from noticing the first symptom, was approximately 2 and a half months earlier for injection procedures compared with surgery. Though surgery may be effective for many patients, it may be associated with complications and the possibility of penile shortening with some procedures [14-16]. It is generally reserved for patients in the chronic phase of PD with deformity and interference in sexual function, and so effective nonsurgical treatment for PD is needed [14].

A major strength of the current study is the use of a web-based survey to recruit a large, population-based sample of participants who were representative of the general US adult male population, which has been lacking in the current PD epidemiological literature. The survey had a high response rate, and the participant responses provided the first available population-based prevalence and incidence estimates for PD in the US. A weakness of the current study is the small number of participant responses for some of the measured outcomes (e.g., surgery). Oversampling of more severe cases of PD may have occurred in the Phase 2 survey; all survey respondents in Phase 1 who reported a diagnosis of PD or treatment for PD were invited to participate in Phase 2, whereas a subsample of participants reporting only symptoms were randomly selected for participation in Phase 2. Finally, participants self-reported their diagnoses and symptoms of PD through a process that allowed for respondent confidentiality (respondents were able to skip over any questions they did not feel comfortable answering or stop the survey at any time) which may have led to under- or overreporting on the survey. Additional problems with patient self-reporting could include misinterpretation of PD-specific symptoms or imperfect recall when symptoms occurred.

\section{Conclusion}

This study is the first large-scale, web-based population survey of PD among a representative sample of US adult men. The patient-reported prevalence of PD ranged from $0.5 \%$ to $13 \%$, depending on how the occurrence of PD was defined. One-third of participants reporting PD also reported interference with sexual activities. More than $90 \%$ of PD patients who sought medical care for penile symptoms did not receive a diagnosis of $\mathrm{PD}$, and approximately $75 \%$ did not receive any treatment from the first doctor seen. Study findings suggest that PD may be underdiagnosed and undertreated in the US and point to the need for better awareness of PD and related treatment options among health care professionals.

\section{Appendix}

\section{A. Peyronie's Disease Survey}

For more details see Supplementary Material available online at doi:10.1155/2011/282503.

\section{Authors' Contributions}

The authors of this paper adhere to Good Publication Practice Guidelines for pharmaceutical companies. D. B. DiBenedetti and L. Zografos were responsible for conceptualizing, organizing, and executing research project; D. B. DiBenedetti was responsible for interpreting and reviewing analyses, preparing initial paper drafts. X. Zhou was responsible for stratified sampling design and analysis plan. X. Zhou and R. Ziemiecki were responsible for executing analyses, interpreting data, and revising manuscript. D. Nguyen was responsible for funding of the current study, reviewing the study report, conceptualizing, reviewing, and critiquing manuscript drafts, as well as the decision to submit for publication.

\section{Conflict of Interests}

D. Nguyen was an employee of Auxilium Pharmaceuticals. D. B. DiBenedetti, L. Zografos, R. Ziemiecki, and X. Zhou declare that they have no conflict of interests.

\section{Acknowledgments}

The authors would like to acknowledge Knowledge Networks for the use of the KnowledgePanel and for administering the questionnaire. The authors would also like to thank Drs. Jianmin Wang and Cheryl D. Coon for their assistance in programming and statistical analyses, Dr. Catherine Johannes for her role as an epidemiology consultant, and Dr. Sheri E. Fehnel for her assistance in the design, analysis, and reporting of the study. Writing and editorial assistance was provided by Jennifer Kent, PhD, and Lynanne McGuire, 
PhD, of MedVal Scientific Information Services, LLC, and was funded by Auxilium Pharmaceuticals, Inc.

\section{References}

[1] F. L. Taylor and L. A. Levine, "Peyronie's disease," Urologic Clinics of North America, vol. 34, no. 4, pp. 517-534, 2007.

[2] W. J. G. Hellstrom, "History, epidemiology, and clinical presentation of Peyronie's disease," International Journal of Impotence Research, vol. 15, supplement 5, pp. S91-S92, 2003.

[3] C. J. Smith, C. McMahon, and R. Shabsigh, "Peyronie's disease: the epidemiology, aetiology and clinical evaluation of deformity," BJU International, vol. 95, no. 6, pp. 729-732, 2005.

[4] T. Akman, O. Sanli, A. Kadioglu et al., "Factors affecting the degree of penile deformity in Peyronie's disease: an analysis of 1001 patients," Journal of Andrology, vol. 32, no. 5, pp. 502508, 2011.

[5] R. Rosen, J. Catania, T. Lue et al., "Impact of Peyronie's disease on sexual and psychosocial functioning: qualitative findings in patients and controls," Journal of Sexual Medicine, vol. 5, no. 8, pp. 1977-1984, 2008.

[6] J. F. Smith, T. J. Walsh, S. L. Conti, P. Turek, and T. Lue, "Risk factors for emotional and relationship problems in peyronie's disease," Journal of Sexual Medicine, vol. 5, no. 9, pp. 21792184, 2008.

[7] R. B. Moreland and A. Nehra, "Pathophysiology of Peyronie's disease," International Journal of Impotence Research, vol. 14, no. 5, pp. 406-410, 2002.

[8] N. F. Gonzalez-Cadavid and J. Rajfer, "Mechanisms of disease: new insights into the cellular and molecular pathology of Peyronie's disease," Nature Clinical Practice Urology, vol. 2, no. 6, pp. 291-297, 2005.

[9] J. M. Greenfield and L. A. Levine, "Peyronie's disease: etiology, epidemiology and medical treatment," Urologic Clinics of North America, vol. 32, no. 4, pp. 469-478, 2005.

[10] A. Müller and J. P. Mulhall, "Peyronie's disease intervention trials: methodological challenges and issues," Journal of Sexual Medicine, vol. 6, no. 3, pp. 848-861, 2009.

[11] A. I. El-Sakka and A. A. Yassin, "Conservative treatment for Peyronie's disease: an update," Expert Opinion on Pharmacotherapy, vol. 9, no. 1, pp. 53-63, 2008.

[12] L. A. Levine, M. Newell, and F. L. Taylor, "Penile traction therapy for treatment of peyronie's disease: a single-center pilot study," Journal of Sexual Medicine, vol. 5, no. 6, pp. 1468$1473,2008$.

[13] P. Gontero, M. Di Marco, G. Giubilei et al., "Use of penile extender device in the treatment of penile curvature as a result of Peyronie's disease. Results of a phase II prospective study," Journal of Sexual Medicine, vol. 6, no. 2, pp. 558-566, 2009.

[14] A. Kadioglu, T. Akman, O. Sanli, L. Gurkan, M. Cakan, and M. Celtik, "Surgical treatment of Peyronie's disease: a critical analysis," European Urology, vol. 50, no. 2, pp. 235-248, 2006.

[15] M. R. Abern, J. S. Benson, and L. A. Levine, "Penile shortening after radical prostatectomy and Peyronie's surgery," Current Urology Reports, vol. 10, no. 6, pp. 468-474, 2009.

[16] E. Chung, E. Clendinning, L. Lessard, and G. Brock, "Five-year follow-up of Peyronie's graft surgery: outcomes and patient satisfaction," Journal of Sexual Medicine, vol. 8, no. 2, pp. 594600, 2011.

[17] M. Arafa, H. Eid, A. El-Badry, K. Ezz-Eldine, and R. Shamloul, "The prevalence of Peyronie's disease in diabetic patients with erectile dysfunction," International Journal of Impotence Research, vol. 19, no. 2, pp. 213-217, 2007.

[18] A. I. El-Sakka, "Prevalence of Peyronie's disease among patients with erectile dysfunction," European Urology, vol. 49, no. 3, pp. 564-569, 2006.

[19] G. La Pera, E. S. Pescatori, M. Calabrese et al., "Peyronie's disease: prevalence and association with cigarette smoking: a multicenter population-based study in men aged 50-69 years," European Urology, vol. 40, no. 5, pp. 525-530, 2001.

[20] M. B. Lindsay, D. M. Schain, P. Grambsch, R. C. Benson, C. M. Beard, and L. T. Kurland, "The incidence of Peyronie's disease in Rochester, Minnesota, 1950 through 1984," Journal of Urology, vol. 146, no. 4, pp. 1007-1009, 1991.

[21] J. P. Mulhall, S. D. Creech, S. A. Boorjian et al., "Subjective and objective analysis of the prevalence of Peyronie's disease in a population of men presenting for prostate cancer screening," Journal of Urology, vol. 171, no. 6, pp. 2350-2353, 2004.

[22] E. L. Rhoden, C. Teloken, H. Y. Ting, M. L. Lucas, C. Teodósio da Ros, and C. Ary Vargas Souto, "Prevalence of Peyronie's disease in men over 50-y-old from Southern Brazil," International Journal of Impotence Research, vol. 13, no. 5, pp. 291-293, 2001.

[23] U. Schwarzer, F. Sommer, T. Klotz, M. Braun, B. Reifenrath, and U. Engelmann, "The prevalence of Peyronie's disease: results of a large survey," BJU International, vol. 88, no. 7, pp. 727-730, 2001.

[24] F. Sommer, U. Schwarzer, G. Wassmer et al., "Epidemiology of Peyronie's disease," International Journal of Impotence Research, vol. 14, no. 5, pp. 379-383, 2002.

[25] A. Kadioglu and O. Sanli, "Epidemiology of Peyronie's disease," in Peyronie's Disease: A Guide to Clinical Management, L. A. Levine, Ed., pp. 9-18, Humana Press, Totowa, NJ, USA, 2007.

[26] Knowledge Networks, "Methodological papers, presentations, and articles on KnowledgePanel," April 2011, http://www. knowledgenetworks.com/ganp/reviewer-info.html.

[27] A. J. Rigby, J. Ma, and R. S. Stafford, "Women's awareness and knowledge of hormone therapy post-Women's Health Initiative," Menopause, vol. 14, no. 5, pp. 853-858, 2007.

[28] R. E. Williams, L. Kalilani, D. B. DiBenedetti et al., "Frequency and severity of vasomotor symptoms among peri- and postmenopausal women in the United States," Climacteric, vol. 11, no. 1, pp. 32-43, 2008.

[29] N. Santoro and J. Komi, "Prevalence and impact of vaginal symptoms among postmenopausal women," Journal of Sexual Medicine, vol. 6, no. 8, pp. 2133-2142, 2009.

[30] S. Greenland and K. J. Rothman, "Introduction to stratified analysis," in Modern Epidemiology, K. J. Rothman and S. Greenland, Eds., pp. 253-279, Lippincott-Raven, Philadelphia, Pa, USA, 1998.

[31] J. C. LaRochelle and L. A. Levine, "A survey of primarycare physicians and urologists regarding Peyronie's disease," Journal of Sexual Medicine, vol. 4, no. 4, pp. 1167-1173, 2007.

[32] L. A. Levine, C. R. Estrada, D. W. Storm, and T. G. Matkov, "Peyronie disease in younger men: characteristics and treatment results," Journal of Andrology, vol. 24, no. 1, pp. 2732, 2003.

[33] J. F. Smith, T. J. Walsh, and T. F. Lue, "Peyronie's disease: a critical appraisal of current diagnosis and treatment," International Journal of Impotence Research, vol. 20, no. 5, pp. 445-459, 2008.

[34] F. Sasso, G. Gulino, R. Falabella et al., "Peyronie's disease: lights and shadows," Urologia Internationalis, vol. 78, no. 1, pp. $1-9,2007$. 
[35] J. P. Mulhall, B. Alex, and J. M. Choi, "Predicting delay in presentation in men with peyronie's disease," Journal of Sexual Medicine, vol. 7, no. 6, pp. 2226-2230, 2010.

[36] Z. Maan, M. Arya, I. Shergill, J. V. Joseph, and H. R. H. Patel, "Peyronie's disease: an update of the medical management," Expert Opinion on Pharmacotherapy, vol. 5, no. 4, pp. 799-805, 2004.

[37] D. Ralph, N. Gonzalez-Cadavid, V. Mirone et al., "The management of Peyronie's disease: evidence-based 2010 guidelines," Journal of Sexual Medicine, vol. 7, no. 7, pp. 2359-2374, 2010.

[38] M. R. Abern and L. A. Levine, "Peyronie's disease: evaluation and review of nonsurgical therapy," The Scientific World Journal, vol. 9, pp. 665-675, 2009. 


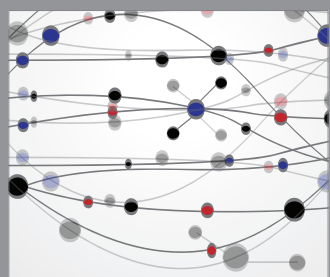

The Scientific World Journal
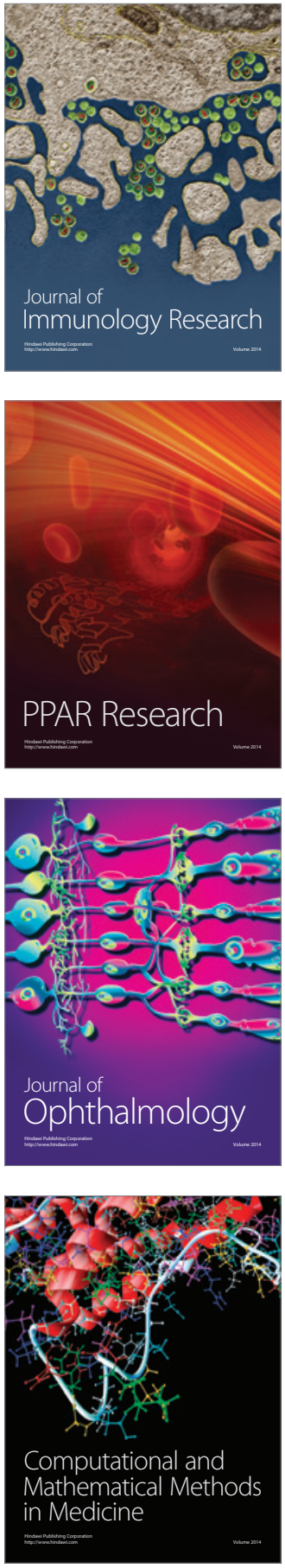

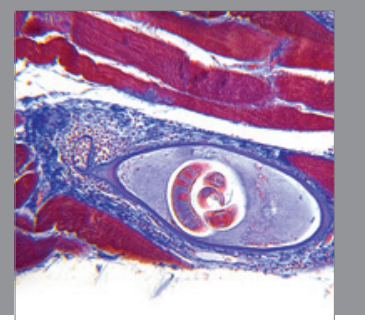

Gastroenterology

Research and Practice
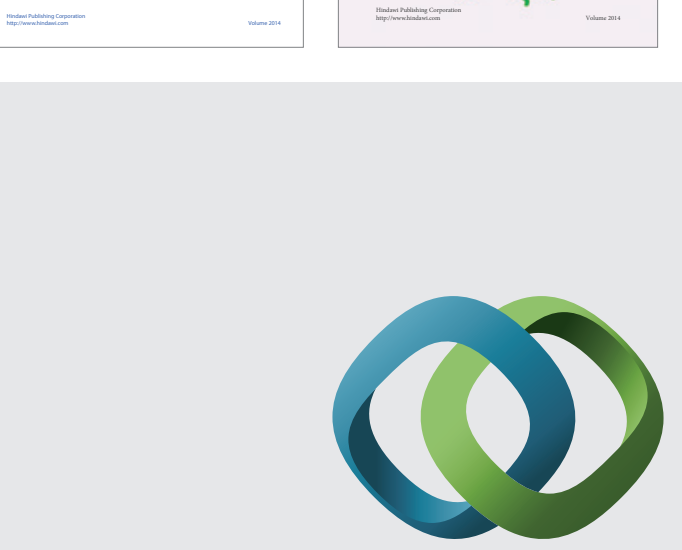

\section{Hindawi}

Submit your manuscripts at

http://www.hindawi.com
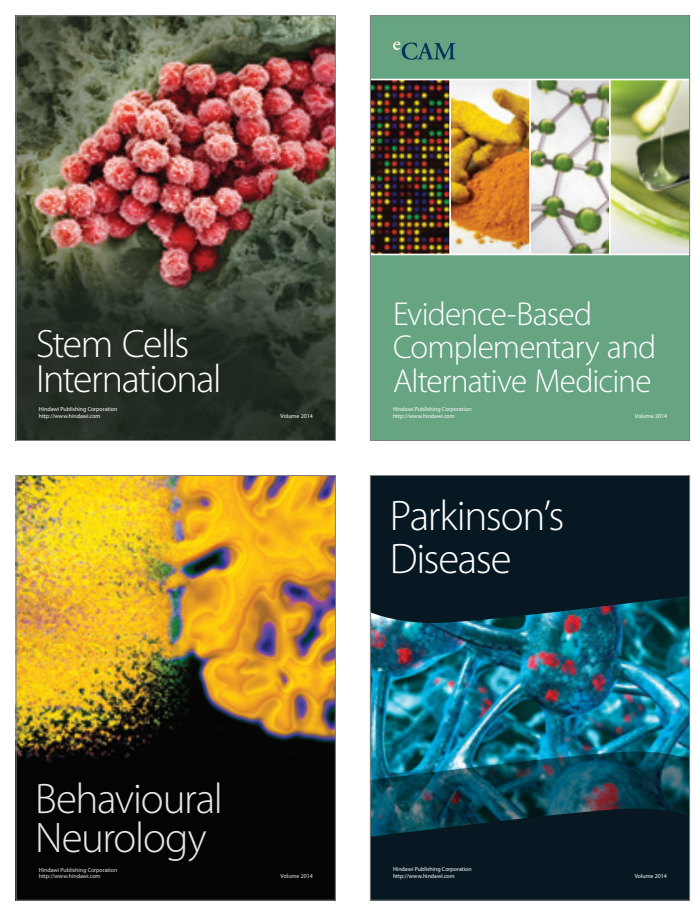

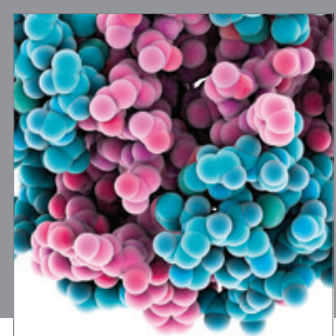

Journal of
Diabetes Research

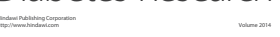

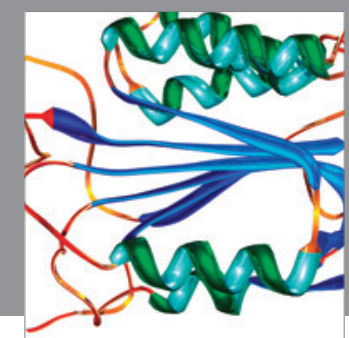

Disease Markers
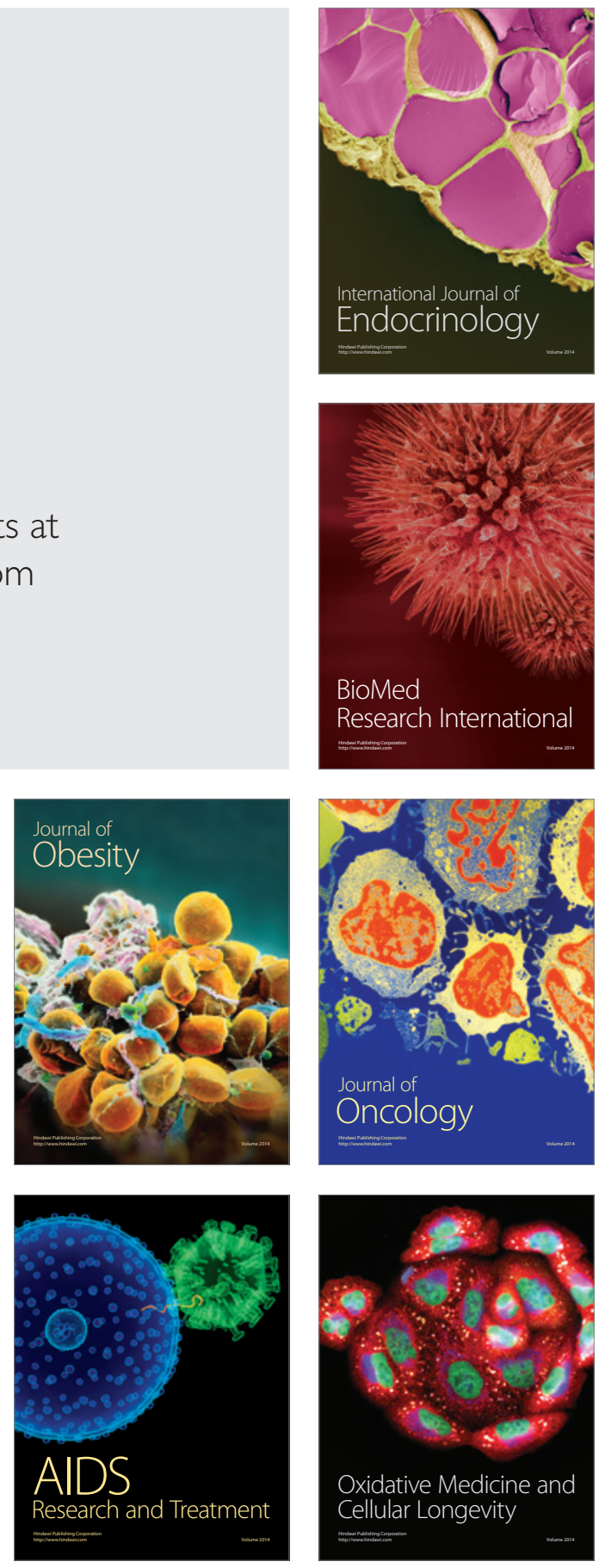